\section{Hubert de Givenchy}

Museo Thyssen-Bornemisza. Madrid

Del 22 de octubre de 2014 al 18 de enero de 2015

¿Una exposición homenaje a Hubert de Givenchy? Más bien, según el comisario Eloy Martínez de la Pera, un homenaje a todos los artesanos que hicieron posibles estas creaciones, a todas las clientas del modisto francés y, en definitiva, a todo el mundo que rodeó, hasta 1995, al coutiere. El propio Givenchy ha formado parte de la ejecución de todo este entramado mágico construido en el Museo Thyssen-Bornemisza de Madrid; quizá, por ello, exista más modestia que soberbia en el discurso expositivo.

Dentro de la llamada museografía crítica ${ }^{1}$, la exposición ha buscado la elegancia en clave romántica. El blanco como fondo y el dorado puntual son las bases de tan delicado espectáculo. Entre tanto, las flores endulzan la escenografía, saltándose a la torera los dictámenes «balenciaguescos» de la ausencia del detalle innecesario; aunque hay que reconocer que, en este caso, la belleza justifica el aderezo. Si bien es cierto que Balenciaga está muy presente en toda su trayectoria, ya se advierte desde su primera colección, parte de ella presente en la primera sala de la muestra. Sería en 1952 cuando tendría lugar el nacimiento de la Maison Givenchy. La primera colección fue bautizada como Separates, un prêt-à-porter de lujo que impactó a la prensa. Sin embargo, existía un interés general por la alta costura. Esto llevó a focalizar la Maison hacia directrices más semejantes a las de sus contemporáneos, dejando de lado momentáneamente el proyecto Separates.

Este primer "escaparate» Givenchy es sobrio y elegante, aunque ya despunta su savoir faire a la hora de crear estructuras; como diría Balenciaga: «Arquitecto para los planos" ${ }^{2}$. La colección fue defendida por las más bellas modelos de París y fue todo un éxito, gracias al trabajo de Bettina Grazziani, amiga y encargada de la prensa. A ella debe el nombre la pieza que centra esta primera sala: la blusa blanca Bettina ${ }^{3}$, con volantes en las mangas pero dotada de un gran vanguardismo. Tanto este conjunto como los restantes 94 que nutren la muestra se disponen sobre maniquís y entran en diálogo con pinturas o, como en este caso, fotogra- fías, que ilustran cómo fueron vistos los vestidos en su día puestos sobre las clientas o las modelos.

La elegancia y la sencillez se apoderan de la segunda sala, dotada de piezas realizadas en cuero y piel. Grandes abotonaduras doradas, fuertes contrastes de azules y rojos con blancos, faldas lápiz, rectas y acampanadas, cinturas marcadas suavemente y estampados animales o rayas. Todo ello configura una síntesis de colores que conversan con la obra Segmentos de círculo de László Moholy-Nagy, en la parte más centrada en la peletería por sus tonalidades marrones, y con la obra de Frank Stella, compartiendo juegos lineales, geométricos y cromáticos.

Santa Casilda de Zurbarán abre la siguiente sala titulada «El negro y la sofisticación». La elección de esta obra plantea una lectura que va más allá del diálogo colorista entre modisto y pintor. De acuerdo a lo expuesto por Elio Berhanyer, «Zurbarán fue el primero y el más grande diseñador de moda en España», hasta el punto de sostener que «si hubiera nacido en el siglo XX, hubiera sido como Yves Saint Laurent 0 Dior» ${ }^{4}$. Esta afirmación algo exagerada no deja de ser una puesta en valor del pintor como diseñador; un artista que, fuera de la mímesis de los "vestidos reales", en palabras de Roland Barthes ${ }^{5}$, crea nuevos modelos, diseña. Esta consideración alberga una nueva dimensión si nos fijamos en la producción del pintor extremeño. Su obra no solo modela nuevos planos, capaz de inspirar al maestro de Guetaria, sino que además diserta tejidos barrocos que bien han sido puestos en consonancia con los ricos tejidos lioneses, italianos o suizos elegidos por el diseñador francés. A esos ricos tejidos Givenchy añade fastuosos bordados que en ocasiones incluyen colorista chapería. La opulencia se une, pues, al negro más refinado.

Las originales estructuras que «vanguardizan» la obra de Givenchy en esta sala quedan tremendamente limpias con la utilización del sobrio negro. Si bien es cierto, el grueso de esta sala entendemos que cae en la elección de los tejidos. El diseñador de Beauvais se embelesaba, al igual que lo 


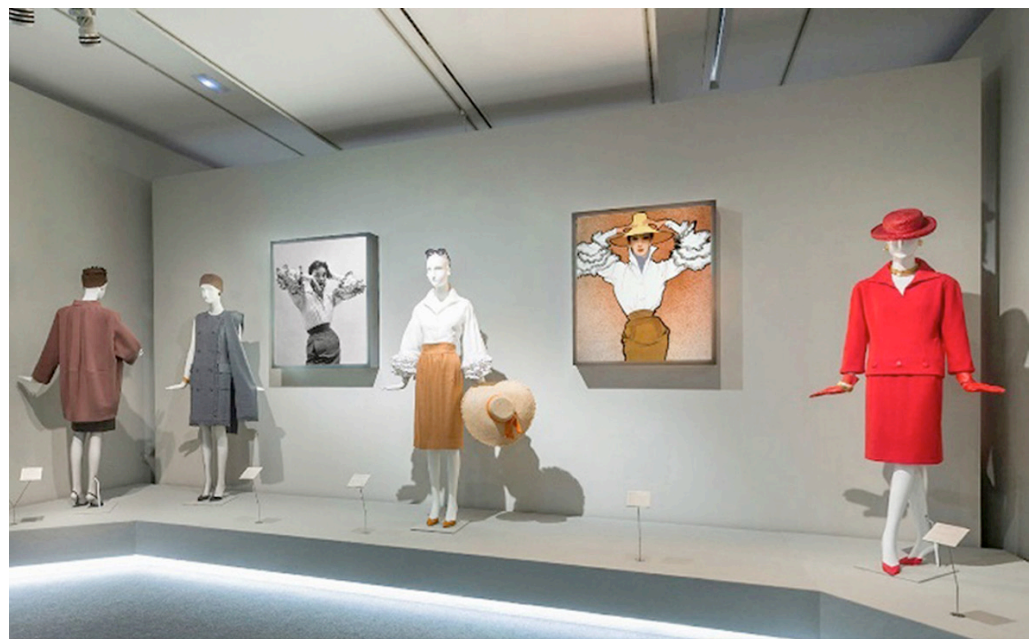

1. Sala 1. Una blusa blanca

hiciera su mentor Balenciaga, con la selección y la utilización de determinados tejidos:

Cuando el estudio se preparaba, y había que diseñar una colección, veía a todos los fabricantes: Gustav Zumsteg, o las sedas de Lyon, o los italianos, que hacían telas absolutamente maravillosas... Y no solo eso. Había que ir hasta sus fábricas para darles ideas, o ver lo que estaban preparando. Era una colaboración maravillosa. Las telas se entregaban en rollos, y cuando llegaban al estudio, era mágico. Esas telas, tan bien preparadas y envueltas, con un olor... Porque la seda tiene un olor particular. Un perfume extraordinario el de los rollos de seda bien embalados. Éramos felices quitando el papel de celofán que los protegía, y extendiendo la tela sobre un maniquí, y viendo el trabajo de los fabricantes de seda de Lyon, o de Suiza, viendo su acabado, esos colores mágicos y brillantes ${ }^{6}$.

Pecando de freudianos, parece existir una base emocional en su infancia. La ciudad de Beauvais, donde nació, era famosa por sus tapices, ligados a la manufactura de los Gobelinos. Su abuelo materno, Jules Badin, administrador de la manufactura, era un gran coleccionista, no solo de muebles y otros bienes, sino también de trajes antiguos y telas preciosas, como los bordados que atesoraba entre sus piezas. Hubert de Givenchy afirma que esa cercanía con el arte fue un auténtico privilegio, lo que sin duda influyó de manera decisiva en su vocación y, por supuesto, en la manera en la que desarrollaría dicha labor ${ }^{7}$.

La cuarta sala viene a ser el homenaje clientelar que Hubert hace a las mujeres de su vida. Curiosamente, este acceso tiene tinte fúnebre: el famoso abrigo negro que Wallis Simpson, duquesa de Windsor, portó en el funeral de su marido. Frente a él, diseños para una sus clientas más conocidas, Jackie Kennedy, fiel seguidora del modisto hasta que consiguió ser primera dama, llegó incluso a saltarse el protocolo vistiendo uno de sus diseños en la presentación de su marido en el Palacio de Versalles, no llevando, como debería haber hecho, un vestido americano. Icónicas piezas se unen con retratos de lo más importantes eventos acaecidos. Se reviven, así, momentos estelares del diseñador.

Cierto es que en la cuarta sala brilla con especial fulgor. Mucho tienen que ver los espejos, presentes en todo el recorrido con objeto de permitir ver la parte no mostrada de los vestidos, provocando además una fuerte multiplicación de la luz. Pero esta sala es especial. En ella se encuentran los vestidos más míticos de la eterna Audrey Herpburn. Destacan muy especialmente el conjunto con antifaz de encaje para la película Cómo robar un millón y, sobre todo, el vestido negro que Audrey llevó en Desayuno con diamantes ${ }^{8}$. Hay un acierto expositivo importante y es poner el vestido de espaldas al espectador. Todo el mundo recuerda la mítica estructura de esta elegante pieza, por ello era justo crear un flash back en el espectador y re- 


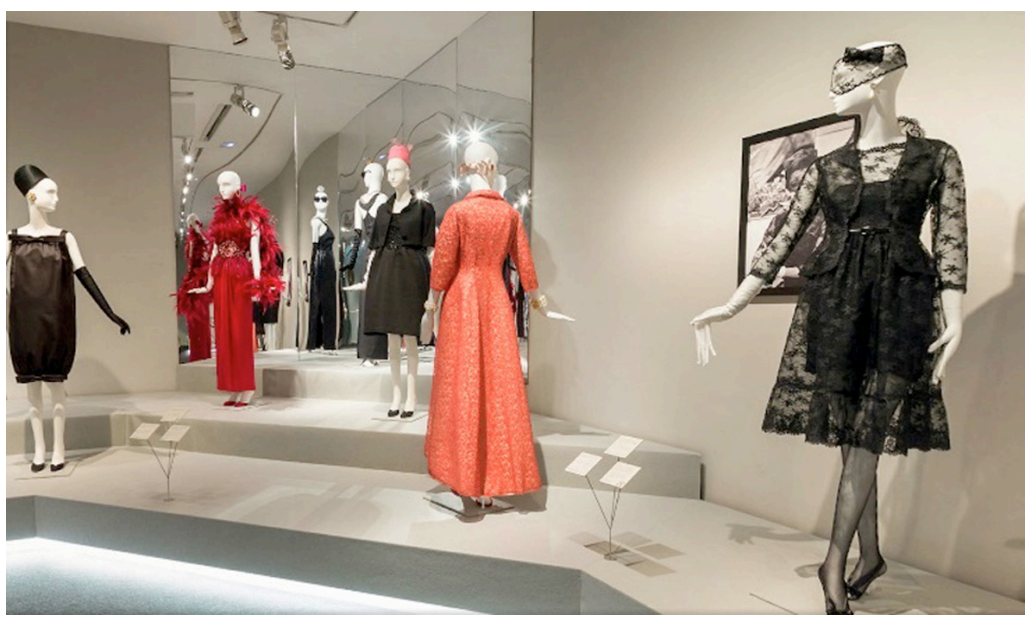

2. Sala 4. Una inolvidable Audrey memorar cuál es, sin duda, el vestido más aclamado de Hubert de Givenchy.

El gusto con el que se han elegido cada una de las piezas en contraste con las pinturas de fondo queda demostrado en la siguiente sala. Tenemos, por un lado, un ambiente floral presidido por la obra Vaso chino con flores de Ambrosius Bosschaert, seguido de los destellos dorados de la obra de Lucio Fontana. Por otro lado, aires coloristas se dibujan en los vestidos de Givenchy junto a obras de Robert y Sonia Delaunay y Theo van Doesburg. La riqueza de los tejidos es especialmente notable en esta sección inundada exclusivamente por alta costura. Además, los complementos que anteriormente completaban la idea de belleza erigida por el diseñador, ahora, más si cabe, brillan con fuerza.

La alta costura de Givenchy continúa estableciendo un diálogo con las obras pictóricas de la siguiente sala. Paisaje mediterráneo de Nicolas de Staël y Pintura sobre fondo blanco de Joan Miró franquean la explosión de color de la obra de Max Ernst, que centra la escenografía. Este telón de fondo da lugar a una mescolanza colorística que conversa, en algunas ocasiones con más acierto que en otras, con los vestidos de Givenchy. Este enfrentamiento pacífico persiste con Abstracción. Resplandor I de Geogia O'Keeffe, una elección cromática más modesta, teniendo en cuenta la riqueza de los vestidos que cobija, especialmente el vestido rojo central con escote en la espalda de bordados barrocos. Por último, Verde sobre morado, de Rothko, atrae la atención de la sala, si es que puede competir en brillantez con el vestido negro azabache con volúmenes violetas expuesto a su izquierda.

El culmen de la exposición llega con el contraste entre el blanco y el negro: «Novias felices» y «La seducción del negro». En esta última sala se dan cita seis vestidos de novia y bastantes más vestidos de alta costura negros, antecedidos por el Retrato de Ana de Hungría, de Hans Maler, y Constelación estructural. Alfa, de Josef Albers, respectivamente; obras seleccionadas, esta vez, con menor acierto. El engalanamiento floral del que antes nos hacíamos eco adquiere ahora su máxima expresión, a través de un vestido de novia que recibe con mesura el acompañamiento natural, pues su confección también planea en estos términos. Por su parte, la elegancia del negro en los vestidos de alta costura permite determinados detalles en otros tonos vibrantes que suman sofisticación a las piezas expuestas.

Un último repaso a la obra de Givenchy sorprende en la octava sala, donde vemos diseños significativos capaces de resumir aspectos propios de su trayectoria. Desde los arquitectónicos volúmenes hasta la riqueza de los tejidos, pasando por exuberantes bordados o el genial uso de intensos colores, todo está presente en esta última muestra. Esta sala permite también conocer otra faceta del diseñador, con la exposición de pamelas y tocados que siguen las premisas marcadas hasta el momento en la indumentaria. Como último detalle, una fotografía gigante del maestro Givenchy rodeado de sus modelos ayuda a contextualizar aún más todo el recorrido expositivo y engrandece la imagen incandescente ofrecida del diseñador francés. 


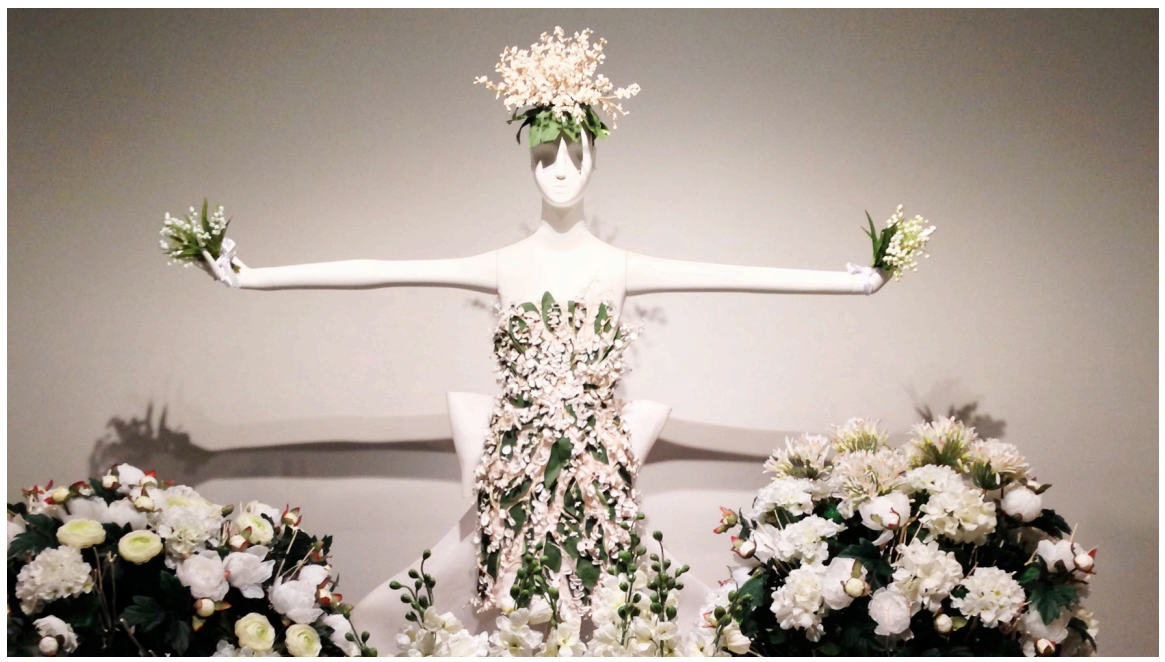

3. Sala 7. Novias felices (detalle)

A todo ello, debemos apostillar un último detalle importantísimo, y es el uso abusivo de la luz en la exposición`. Aunque se trate de tejidos contemporáneos, si queremos que existan más exposiciones antológicas y retrospectivas de Givenchy, debemos conservar acertadamente el legado que este nos deja. Resulta fundamental concienciarnos de los efectos nefastos que puede acarrear la exposición excesiva de las piezas a una luz desmesurada, ya que, al poseer los tejidos un carácter acumulativo, el factor lumínico contribuye negativamente a la decoloración de los tintes ${ }^{10}$. Atendiendo a este hecho, se podrán llevar a cabo más exposiciones de este tipo, en las que se ensalce con maestría la labor fundamental del seguidor más aventajado de Cristóbal Balenciaga y se refuerce nuevamente su papel capital en la historia del arte.

\section{Ismael Amaro Martos \\ Universidad de Jaén}

\section{Notas}

1 LORENTE LORENTE, Jesús Pedro, «El fin del canon moderno y la instauración de otros recursos museográficos», Museo y Territorio, n. ${ }^{4}$, 2011, pp. 124132

2 FIGUERAS, Josefina, Protagonistas de la moda, Madrid, Ediciones Internacionales Universitarias, 2005, p. 38.

3 GIVENCHY, Hubert de, «Rueda de prensa Museo Thyssen-Bornemisza. 20 de octubre de 2014». En: http://pdigital.museothyssen.org/index.html?revista=119360563\&pagina=19067 (Fecha de consulta: 20-01-2015).

4 J. A., «Elio Berhanyer: «Zurbarán fue el primero y el más grande diseñador de moda en España». En: http://www.abcdesevilla.es/cultura/arte/20130505/ sevi-elio-exposicion-moda-201305042245.html (Fecha de consulta: 26-06-2013).

5 BARTHES, Roland, Sistema de la moda, Barcelona, Gustavo Gili, 1978, p. 18.

6 GIVENCHY, «Rueda de prensa Museo...».

7 GIVENCHY, Hubert de, «Introducción». En: http://pdigital.museothyssen.org/index.html?revista=119360563\&pagina=16860 (Fecha de consulta: 21-012015).

8 No se puede asegurar a ciencia cierta que este fuese el vestido que Audrey Herpburn llevó en Desayuno con diamantes. Para el rodaje de la película se le encargaron tres vestidos idénticos al modisto por si ocurría algún percance durante el rodaje. Posteriormente la actriz le daría uno de ellos a Hubert de Givenchy y este se lo donaría al Museo del Traje de Madrid, institución que lo prestó al Museo Thyssen-Bornemisza. El hijo de la actriz conservaría otro de los vestidos y el tercero fue subastado por Christie's por 607.720 euros. LUCEÑO CASALS, Laura, "Vestido de Hubert de Givenchy para Audrey Herpburn en la película Desayuno con diamantes", Modelo del mes. Los modelos más representativos de la exposición, Madrid, Museo del Traje, 2009 , pp. 1- 2.

9 En el Museo del Traje de Madrid, donde se atesora, por ejemplo, en vestido de Desayuno con diamantes, la luz solo alcanza unos niveles de 50 lux de intensidad. PÉREZ DE ANDRÉS, Carmen, «Una visión global sobre aspectos de conservación, restauración y montaje», Indumenta, n. ${ }^{\circ}$ 0, 2007, p. 24.

10 Ibidem. 